\title{
Patient safety: global momentum builds
} Sir Liam Donaldson

\section{The International Alliance for Patient Safety to be established by the World Health Organization indicates its commitment to a global patient safety policy}

n November 2003 an international meeting of major importance took place in London on the theme of patient safety. Policy makers, clinical leaders, and experts from many countries around the world came together to consider the next steps in making resolution WHA 55.18 passed by the World Health Assembly in May $2002^{1}$ an operational reality.

The original resolution urged countries to pay the greatest possible attention to patient safety and requested the Director-General of the World Health Organization to carry out actions including: the development of global norms and standards; the promotion of evidence-based policies and mechanisms to recognise excellence in patient safety internationally; the encouragement of research on the subject; and giving assistance to countries in several key areas.

Since the resolution was passed, the World Health Organization has established work programmes tackling systemic issues such as taxonomy, estimating hazards, and the development of reporting and learning systems. The World Health Organization has also brought together its technical experts in areas such as blood safety, injection safety, vaccine safety, drugs and medicines, making pregnancy safer, and medical devices so that their individual expertise can be harnessed to tackle global patient safety issues.

One of the most significant proposals to emerge from the November 2003 London summit was the establishment of an International Alliance for Patient Safety.

The International Alliance for Patient Safety will be of fundamental importance in facilitating the development of patient safety policy and practice in all member states of the World Health Organization. This will be achieved through the delivery of a number of core functions and short term initiatives as set by the Alliance in an annual work programme. At present a number of working groups have been established to consider possible core functions. The working groups consist of international experts and policy makers from all World Health Organization regions. They are addressing issues such as policy development and monitoring; research; solution development; reporting and learning systems; a specific programme to be designed for developing countries; professional issues; and consumer involvement. Membership of the International Alliance for Patient Safety will be open to all countries, interested bodies, and international experts. Its creation recognises that no single body has the expertise, funding, or research and delivery capabilities to tackle the full range of patient safety issues on a worldwide scale. It will provide a mechanism that can reduce duplication of investment and increase those activities that benefit from economies of scale. The International Alliance for Patient Safety will provide an environment in which major new initiatives can take place that individual partners might not be able or willing to take on alone. It can become a vehicle for the sharing of knowledge and resources to improve effectiveness.

Over the last decade the whole concept of patient safety has been much more widely understood and researched. ${ }^{2}$ The capacity of healthcare systems to change and redesign their systems and ways of working to reduce risks for the patients they serve is a formidable challenge. Harnessing the commitment, expertise, and talent in the field of patient safety across the world provides the opportunity to make that challenge a global one. The involvement and commitment of the World Health Organization signals that the time is now right for the global patient safety movement to get to work and start saving lives.

Qual Saf Health Care 2004;13:86. doi: 10.1136/qshc.2004.010587

Correspondence to: Professor Sir L J Donaldson, Chief Medical Officer, Department of Health, Richmond House, 79 Whitehall, London SWIA 2NS, UK; philipp@who.int

\section{REFERENCES}

1 World Health Assembly Resolution WHA55.18. Quality of care: patient safety. www.who.int/gb/ QB_WHA/PDF/WHA55/ewha5518.pdf.

2 Moss F. Working differently for better, safer care. Qual Saf Health Care 2003;12(Suppl 1):i1.

\section{Pursuing patient safety}

\section{B Malone}

\section{Role of nurses in improving the quality of care}

W hether you work as a nurse in the US, the UK, or elsewhere in the world, you will be familiar with the often quoted words of Florence Nightingale (1869): "First do [the patient] no harm". Reflecting upon the fundamentals of good nursing, Nightingale was in no doubt that the moral, professional, and individual responsibility of nurses was to ensure that no unintentional harm came to the patients in their care.

Those of us familiar with Nightingale's influence would also be aware that her understanding of patient safety extended far beyond the individual behaviour, knowledge, and skill of the nurse. She wrote widely about the need for effective hygiene and sanitation, good food, lighting and ventilation in hospitals; effective administration; the collection and use of routine statistics; and strong leadership. Nightingale was not only the first nurse-she was the first nurse researcher. ${ }^{1}$

It is chastening to realise that, more than a century later, we are still striving to understand how we can improve patient safety in our hospitals and healthcare settings. This was clearly reflected in my appointment in 1997 to President Clinton's Advisory Commission on Consumer Protection and 
Quality in the Health Care Industry. ${ }^{2}$ As a Commission, we found that it was impossible to get to issues of quality without going through the essentials of safety, reducing the unacceptable level of errors. Two major initiatives resulted from the Commission's work: (1) a patient's Bill of Rights that focused on patient centred health care; and (2) a Forum for Health Care Quality that was created to identify core quality measures for standardised reporting and to promote the focused development of enhanced measures for the future. Both used safety as an underlying fundamental principle.

Building on this initial work, three recent publications by the Institute of Medicine (IOM) in the US ${ }^{3-5}$ outline the challenges we have still to overcome. "To Err is Human: Building a Safer Health System $^{\prime \prime 3}$ addressed the broad environment of policy, payment, regulation, accreditation, and other external factors that shape the context in which healthcare organisations deliver care. From this national blueprint for patient safety the second document "Crossing the Quality Chasm: A New Health System for the 21st Century"4 focused on how the experiences of individual patients and the work practices of small units of care (microsystems) could deliver more consistent safe, effective health care.

The most recent publication, "Keeping Patients Safe: Transforming the Work Environment of Nurses", ${ }^{\prime}$ addresses the middle layer between individual patient and team experiences and the national policy level-that is, the organisations that house the microsystems. The report specifically looks at four key dimensions of the organisation: its management practices, workforce deployment patterns, work design, and organisational culture.

A series of recommendations covering five core areas have been identified from the evidence as improving patient safety:
- commitment to strong, effective nurse leadership at every level of decision making that links to patient care;

- investment in evidence-based methods that can determine and monitor safe nurse staffing levels, taking into account skill mix, case mix, and good working practices;

- further development of better design of nursing working practices and the work environment to mitigate errors;

- transformation of working cultures to embrace a culture of safety which recognises that most errors are created by systematic organisational defects in work processes and not by individuals, where staff feel supported, and in which there is continuous learning;

- the need to improve the evidence base around the delivery of health services, expert nursing care, and patient safety.

Such recommendations are pertinent to our experiences of safety and care across the entire world. The challenges laid out so clearly in the IOM documents speak to every government, every provider of health care, every professional association, and every healthcare organisation. The establishment of the National Patient Safety Agency in the UK is one of many UK responses to the growing national agenda for patient safety. The work of the Modernisation Agency around the Changing Workforce Programme and the multiple leadership initiatives again feed into the organisation and microsystem activity necessary for wide scale change.

But, despite all these laudable pursuits and excellent initiatives, there may still be some very simple actions that we could take to offer the promise so elegantly articulated by Nightingalefor example:
- ensure that nurses' views regarding safety are heard at every decision making meeting;

- develop and routinely monitor patient safety indicators which are also nurse sensitive indicators such as hospital acquired infection rates, the incidence of pressure ulcers, medication errors, death among surgical inpatients with treatable serious complications (failure to rescue), restraint rates;

- involve the nursing workforce in transforming their own working environment to ensure that it is patient focused and safe (acknowledging the interdependency of nursing and other health interventions).

Much of this transformation work has already begun, but we do need it to be more visible, more valued, and more rigorously pursued to achieve our goal of "first doing no harm". As a nurse, I am a witness and an ongoing participant in the transformation that can result in quality care for all.

Qual Saf Health Care 2004;13:86-87. doi: 10.1136/qshc.2003.009498

Correspondence to: Ms B Malone, Royal College of Nursing, 20 Cavendish Square, London WIG ORN, UK; julia.mountain@rcn. org.uk

\section{REFERENCES}

1 Neuhauser D. Florence Nightingale gets no respect: as a statistician that is. Qual Saf Health Care 2003;12:317.

2 Institute of Medicine. Quality first: better health care for all Americans. Final Report of the President's Advisory Commission on Health Consumer Protection and Quality in the Health Care Industry. Washington, DC: US Government Printing Office, 1998.

3 Institute of Medicine. To err is human: building a safer health system. Washington, DC: National Academy Press, 2000.

4 Institute of Medicine. Crossing the quality chasm: a new health system for the 21st century. Washington, DC: National Academy Press, 2001.

5 Institute of Medicine. Keeping patients safe: transforming the work environment of nurses. Washington, DC: National Academy Press, 2003. 